\title{
Everything you always wanted to Know about Black Dye (but Were Afraid to Ask): A DFT/TDDFT Investigation
}

\author{
Simona Fantacci*, Maria G. Lobello, and Filippo De Angelis ${ }^{\star}$
}

\begin{abstract}
We report an exhaustive theoretical and computational investigation of the electronic, optical, redox and acid-base properties, along with the adsorption mode on $\mathrm{TiO}_{2}$, of Black Dye (BD), the prototypical panchromatic dye for solar cell applications. We investigated in detail the variation of the relevant dye properties as a function of the solution $\mathrm{pH}$, corresponding to the stepwise deprotonation of the carboxylic groups. Our results reproduced the expected blue-shift of the optical absorption spectrum and the experimental trend of oxidation potentials by increasing $\mathrm{pH}$, which turned both out to be in excellent agreement with experimental values. Also, our calculated excited state oxidation potential is in good agreement with available experimental data. We then looked at the $\mathrm{pK}_{\mathrm{a}}$ of the various deprotonation steps, finding lowest $\mathrm{pK}_{\mathrm{a}}$ values for the stepwise dissociation of three protons of 2.71, 3.69 and 5.20, in excellent agreement with experimental $\mathrm{pK}_{\mathrm{a}}$ values of 3 and 5 , for two and one protons dissociation, respectively. We finally investigated the adsorption of $\mathrm{BD}_{\mathrm{a}}$ on $\mathrm{TiO}_{2}$, finding the most stable adsorption to occur via two dissociated monodentate carboxylic groups. Inspection of the electronic structure and alignment of energy levels for N719 and BD revealed a reduced driving force for electron injection in the latter dye, which could possibly lead to energetically unfavorable electron transfer from the excited dye to the $\mathrm{TiO}_{2}$ conduction band. Our results may constitute a reference study for future investigations and optimization of BD-based dyesensitized solar cells.
\end{abstract}

Keywords: Acid-base properties · Black Dye $\cdot \mathrm{DFT}$ - Electronic and optical properties $\cdot \mathrm{TiO}_{2}$ adsorption

\section{Introduction}

A new and bright interest has been addressed towards $\mathrm{Ru}(\mathrm{II})$ and $\mathrm{Os}(\mathrm{II})$ panchromatic dyes as sensitizers in dye-sensitized solar cells (DSCs). ${ }^{[1-9]}$ The DSC technology, devised in 1991 by O'Regan and Grätzel, ${ }^{, 10]}$ allow the direct conversion of solar light into electricity. DSCs are devices constituted by two sandwich electrodes of a transparent conductive oxide (FTO or ITO). The anode shows a layer of nanostructured semiconductor metal oxide, which is sensitized by a molecular dye that works as light-absorber and charge-separator at the interface between the two materials. ${ }^{[11]} \mathrm{A}$ redox mediator deals with the regeneration of the oxidized dye and the transport of the hole towards the cathode, where a catalyst (usually metallic platinum) regenerates the oxidized electrolyte or hole conductor closing the circuit.[12,13]

\footnotetext{
${ }^{*}$ Correspondence: Dr. S. Fantacci; Dr. F. De Angelis Computational Laboratory for Hybrid/Organic Photovoltaics (CLHYO)

Istituto CNR di Scienze e Tecnologie Molecolari

Via Elce di Sotto 8

I-06123, Perugia, Italy

Tel.: +390755855523

E-mail: simona@thch.unipg.it; filippo@thch.unipg.it
}

Record DSC efficiencies exceeding $11 \%$, have been obtained using $\mathrm{Ru}(\mathrm{II})$-dyes on $\mathrm{TiO}_{2}$ in combination with a liquid electrolyte based on the $\mathrm{I}^{-} / \mathrm{I}_{3}^{-}$couple in volatile organic solvents. $[14,15]$ Very recently the combination of new Zn-porphyrin dyes in combination with an alternative $\mathrm{Co}(\mathrm{II}) /$ Co(III) redox couple has provided DSC efficiency higher than $12 \% .{ }^{[16]}$ The interplay between the various components seems therefore crucial to reach high cell efficiency, but the research towards new dyes with target features remains a very active field.

One of the major issues for further improvement in the DSCs is the design of panchromatic sensitizers which absorb the lower energy portion of the visible radiation spectrum up to near-IR (NIR). In this respect, $\left[\mathrm{Ru}\left(\mathrm{H}_{3} \text { tcterpy }\right)(\mathrm{NCS})_{3}\right]^{-}$ (tcterpy $=4,4^{\prime}, 4^{\prime \prime}$-tricarboxy-2,2':6', 2"'terpyridine), ${ }^{[1,9]}$ also known as N749 or Black Dye (BD), has attracted considerable experimental interest. ${ }^{[17-26]}$ As a matter of fact, BD is nowadays employed in the DSC that provides the highest certified efficiency of $11.4 \% .[15]$

One interesting feature of the $\mathrm{BD}$ is the demonstrated sensitivity of these system properties to the solution $\mathrm{pH}$. This is related to the three carboxylic groups on the tpy ligand, which directly influence the energy and composition of the $\pi^{*}$ orbitals of the ligand. As a matter of fact, the optical absorption spectra measured as a function of the $\mathrm{pH}$ show a red shift of the absorption maxima upon decreasing the solution $\mathrm{pH} .{ }^{[1]}$ Also, the fundamental energetic parameters ruling the electron injection and regeneration steps, i.e. the ground state oxidation potential (GSOP) and excited state oxidation potential (ESOP), substantially vary with the $\mathrm{pH} \cdot{ }^{[1,24]}$ The ground state $\mathrm{pK}_{\mathrm{a}} \mathrm{s}$ of the BD have been measured, finding two separate values corresponding to the exchange of one and two protons, respectively. ${ }^{[1]}$ The acid-base chemistry of the tpy ligand was found to have a direct connection with fundamental DSC operational mechanism details, such as the charge generation efficiency ${ }^{[24,25]}$ and the electron injection yield. ${ }^{[17]}$

Due to the great experimental interest and the high efficiency of the BD, various theoretical studies on this system have been reported.[27-36] In particular, a few computational works have been focused on the electronic structure of the $\mathrm{BD}^{[28]}$ and on the optical properties of the monoprotonated ${ }^{[29]}$ and on the fully protonated, di- and mono-protonated and fully deprotonated forms of BD. ${ }^{[31]}$ Also a study on the electronic structure and absorption spectra of linkage isomers of $\mathrm{BD}$ has been reported.[28] Notably, also the interaction of the BD with iodine and the formation of hydrogen-bonded dimers of the BD and chenodeoxycholic acid have been recently computationally explored. ${ }^{[32,33]}$ 
Very recently, the adsorption mode of the $\mathrm{BD}$ on $\mathrm{TiO}_{2}$ has also been computationally investigated using both cluster and periodic boundary conditions approaches. ${ }^{[34-36]}$ The optical absorption spectrum of the BD adsorbed onto $\mathrm{TiO}_{2}$ clusters $\left(\mathrm{BD} @ \mathrm{TiO}_{2}\right)$ has also been calculated, ${ }^{[35]}$ although a simplified $\mathrm{TiO}_{2}$ model was employed which did not allow full exploration of the possible dye binding modes. ${ }^{[36]}$ The work by Sodeyama et al. on the other hand, explored in detail the possible dye binding modes on $\mathrm{TiO}_{2}$ in vacuo, but reported simulated optical properties for the isolated dye at their adsorption geometry. ${ }^{[34]}$ The authors concluded that for the fully protonated $\mathrm{BD}$, a molecular monodentate adsorption mode is the more stable structure, in contrast to most previous reports concerning carboxylic anchoring groups.

Although the previous theoretical and computational work on the BD in its various protonated forms has contributed to shed some light on the dependency of the structural, adsorption and electronic/optical properties of such a system on the $\mathrm{pH}$ of the solution, a systematic investigation of the BD acid-base properties and of their punctual relation to the optical spectra and ground and excited state oxidation potential is still missing. In this article we thus aim to fill this gap, reporting a thorough DFT/TDDFT investigation of all the possible species resulting from deprotonation of the BD carboxylic groups, along with the determination of the ground state $\mathrm{pK}$ associated to the sequential deprotonation steps along with their impact on the energy levels and optical properties of the BD. We also complement our study by investigating, for the BD carrying two protons, a few possible adsorption modes onto the $\mathrm{TiO}_{2}$ surface and the related electronic structure properties.

\section{Methods and Computational Details}

All the calculations on the molecular systems were performed using the Gaussian03 (G03) program package. ${ }^{[37]}$ The molecular structure of the BD_nHcomplexes in their singlet ground state lowest triplet excited state, with $\mathrm{n}=3,2,1,0$ were optimized in vacuo and water solution, using the $\mathrm{B} 3 \mathrm{LYP}^{[38]}$ exchange-correlation (xc) functional, using a LANL2DZ[39] basis set for all atoms along with the corresponding pseudopotentials for $\mathrm{Ru}$. To determine $\mathrm{pK}_{\mathrm{a}}$ values, single point calculations were performed on the optimized geometries using a LANL2DZ basis set and pseudopotential for $\mathrm{Ru}$ augmented with a $6-31+\mathrm{G}^{*[40,41]}$ basis sets for N, C, S, O and $\mathrm{H}$ atoms. Solvation effects were included by means of the conductor-like polarizable continuum model (CPCM), ${ }^{[22,43]}$ as implemented in G03. To simulate the optical absorption spectra, TDDFT calculations of the 70 lowest singlet-singlet excitations were performed in water solution, on the structure optimized in vacuum, using a DGDZVP basis set ${ }^{[44]}$ and the B3LYP $x c$ functional, along with default UA0 radii.

To determine the $\mathrm{pK}_{\mathrm{a}}$ constants associated with all the possible deprotonation steps of BD, geometry optimizations were performed in water solution by means of the conductor-like polarizable continuum model (CPCM) using three different solvation options: the default UA0 solvation radii, specific spheres (SPH) added on the hydrogen mostly involved in the reaction, and UAHF solvation radii. ${ }^{[45]}$ Following the thermodynamic cycle described in detail in ref. [46], the Gibbs free energy in solution of species $i\left(\mathrm{G}_{\text {sol }}^{\mathrm{i}}\right)$ is defined as: $\mathrm{G}_{\text {sol }}^{\mathrm{i}}$ $=\mathrm{G}_{\text {vac }}^{\mathrm{i}}+\Delta \mathrm{G}_{\text {solv }}^{\mathrm{i}}$, where $\mathrm{G}_{\text {vac }}^{\mathrm{i}}$ is the Gibbs free energy of species $i$ in vacuum and $\Delta \mathrm{G}_{\text {solv }}^{\mathrm{i}}$ is the free energy of solvation. $\mathrm{G}_{\text {vac }}^{\mathrm{i}}$ is computed at the geometry optimized in vacuum, followed by frequency calculations to take into account the vibrational contribution to the total partition function. $\Delta \mathrm{G}^{\mathrm{i}}{ }_{\text {solv }}$ is directly calculated by a CPCM single-point calculation in aqueous solution together with a reference calculation in vacuum, at the geometry optimized in solution. For the proton $\left(\mathrm{H}^{+}\right)$free-energy values, we used the known experimental data: $\mathrm{G}_{\mathrm{H}_{+}}=-6.28 \mathrm{kcal} / \mathrm{mol}^{[47]}$ and $\Delta \mathrm{G}_{\mathrm{so}}$ $=-263.98 \mathrm{kcal} / \mathrm{mol} \cdot{ }^{[48]} \mathrm{A}$ term $-\mathrm{RT} \ln 24.46$ was added to account for the standard state corrections on the free energy of the proton passing from the gas phase $(1 \mathrm{P}, \mathrm{bar})$ to the reference liquid phase $(1 \mathrm{M}, \mathrm{mol} / \mathrm{l})$.

We rigorously determined the GSOP by computing the free energy difference between the neutral and the oxidized GS species, $\left(G^{0}-G^{+}\right)_{\mathrm{GS}}{ }^{[49]}$ The free energy in solution of the $\mathrm{i}$-th species $\left(\mathrm{G}_{\text {sol }}^{\mathrm{i}}\right)$, was obtained using the procedure above. The ESOP was obtained by adding the $\mathrm{E}_{0-0}$ transition to the GSOP. ${ }^{[49]} \mathrm{E}_{0-0}$ was obtained by performing a geometry optimization of the lowest SCF triplet excited state, and by adding to the lowest excitation energy calculated at the excited state geometry the ground state energy difference between the singlet and triplet geometries, $\Delta \mathrm{E}_{\text {dist }}$ (Fig. 1). Analogously to the $\mathrm{pK}_{\mathrm{a}}$ calculations, we also checked the effect of different solvation radii (UA0, UAHF and $\mathrm{SPH}$ ) on the TDDFT calculations, finding comparable data obtained at the different level of calculations. We limit our discussion to GSOP and ESOP values obtained with the SPH radii.

To model the $\mathrm{TiO}_{2}$ surface, we consider a $\left(\mathrm{TiO}_{2}\right)_{82}$ cluster, obtained by appropriately 'cutting' an anatase slab exposing the majority (101) surface. ${ }^{[50]}$ Following the work by Persson et al., ${ }^{[51]}$ we consider a

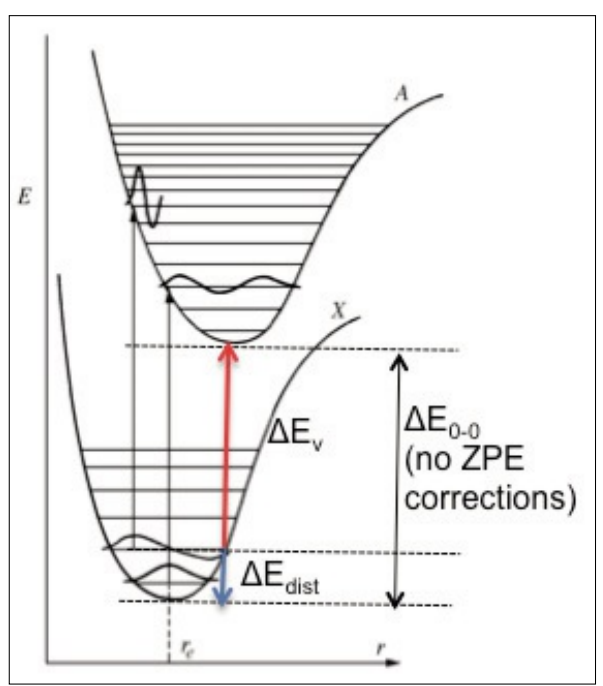

Fig. 1. Schematic representation of the two contributions to $\mathrm{E}_{0-0}$ : (in red) the vertical excitation energy at the excited state optimized geometry $\left(\Delta \mathrm{E}_{\mathrm{v}}\right)$ and (in blue) the 'distortion energy' of the ground state, $\Delta \mathrm{E}_{\text {dist }}$

neutral stoichiometric $\mathrm{TiO}_{2}$ cluster with no saturating atoms or groups at the cluster border. These models have been shown to accurately reproduce the electronic and structural properties of $\mathrm{TiO}_{2}$ anatase. ${ }^{[51]}$ The employed $\left(\mathrm{TiO}_{2}\right)_{82}$ model is an almost square $\mathrm{TiO}_{2}$ (101) two-layer anatase slab of $c a .2 \mathrm{~nm}$ side, with three rows of fiveand six-coordinated surface Ti sites, which is large enough to avoid possible spurious dye/titania interactions at the cluster border due to the finite cluster size. The calculated dipole moment for our $\left(\mathrm{TiO}_{2}\right)_{82}$ cluster is correctly found to be almost vanishing in all directions $(0.5,0.7$, and $0.8 \mathrm{D}$ for $\mathrm{x}, \mathrm{y}$, and $\mathrm{z}$, the latter corresponding to the surface normal). The $\left(\mathrm{TiO}_{2}\right)_{82}$ cluster has been already successfully employed to study the adsorption mode, the electronic structure and the absorption spectrum of N719 on titania, ${ }^{[52,53]}$ we thus can be confident of the accuracy of the $\mathrm{TiO}_{2}$ model.

\section{Results and Discussion}

\subsection{Molecular Structure of the Isolated BD}

The optimized molecular structures of BD_nH, with $\mathrm{n}=3,2,1,0$ complexes are reported in Fig. 2, along with their relative energies in vacuo and in water solution. For BD_2H and BD_1H two different isomers are possible, BD_nHx, where $\mathrm{x}=1$ and $\mathrm{c}$ indicate the lateral and central position of the present hydrogen atoms, respectively. In Fig. 2, for the two isomers of BD_2H and BD_1H the relative free energies including the thermal corrections $(\mathrm{G})$ and the energies in solution are reported. We have established that the species BD_2Hll and the BD_1Hc are the most stable diproton- 
ated and monoprotonated isomers, both considering the energy in solution, and the free energy including the thermal contribution.

\subsection{Acid-Base Properties}

The BD shows three carboxylic groups on the 4,4',4"'-positions of the terpyridine ligand. In principle, the deprotonation could be: 1) completely stepwise, characterized by three protonation equilibria related to the three carboxylic groups; 2) simultaneous, only one equilibrium constant is expected; 3) a mixed two-step process, with a simultaneous double deprotonation involving the two equivalent carboxylic groups of the peripheral pyridines and a deprotonation occurring on the central carboxyl.

Experimentally, the $\mathrm{pK}_{\mathrm{a}}$ constants were spectrophotometrically determined by plotting the $\mathrm{BD}$ absorbance change as a function of $\mathrm{pH}$ at 620 and $338 \mathrm{~nm} .^{[1]}$ The two inflection points shown by the titration curves at $\mathrm{pH}=3.3$ and $5.0 \pm 0.1$ were associated with two $\mathrm{pK}$ constants, therefore with two protonation equilibria, of which one is a concomitant two-proton process. ${ }^{[1]}$ In particular, the experimental $\mathrm{pK}_{\mathrm{a}}$ of 3.3 was assigned to the concurrent dissociation of two protons coming from the peripheral pyridines, due to the similarity with the $\mathrm{pK}_{\mathrm{a}} \mathrm{s}$ observed for $\mathrm{Ru}-4-4$ '-dicarboxy2,2'-bipyridine ligand, while the $\mathrm{pK}_{\mathrm{a}}$ at 5.0 was assigned to the deprotonation from the central pyridine, trans to the NCS ligand.

In our theoretical approach we considered a completely stepwise deprotonation from the fully protonated BD_3H to the deprotonated $\mathrm{BD} \_\mathrm{OH}$, passing from the mono- and di-protonated species. The $\mathrm{pK}$ constants associated with the mono-deprotonation steps are labeled $\mathrm{pK}_{\mathrm{a} 1}, \mathrm{pK}_{\mathrm{a} 2}$ and $\mathrm{pK}_{23}$. We report in Table 1 the computed $\mathrm{pK}_{\mathrm{a}}$ values obtained considering different solvation radii, $\mathrm{SPH}, \mathrm{UAO}$, and UAHF. We only discuss the results obtained by includ-

Table 1. Calculated $\mathrm{pK}_{\mathrm{a}} \mathrm{s}$ using LANL2DZ and $631+\mathrm{G}^{*}$ basis set and different solvation radii.

\begin{tabular}{|l|c|c|c|}
\hline & \multicolumn{3}{|c|}{$\mathrm{pK}_{\mathrm{a}}$} \\
\hline Acid/base couple & SPH & UA0 & UAHF \\
\hline BD_3H/BD_2Hll & 2.71 & 6.70 & 4.82 \\
\hline BD_3H/BD_2Hlc & 2.82 & 6.81 & 4.82 \\
\hline BD_2Hlc/BD_1Hl & 3.69 & 7.62 & 6.06 \\
\hline BD_2Hlc/BD_1Hc & 3.95 & 7.86 & 6.14 \\
\hline BD_2Hll/BD_1Hl & 3.80 & 7.73 & 6.06 \\
\hline BD_2Hll/BD_1Hc & 4.06 & 7.97 & 6.14 \\
\hline BD_1Hl/BD_0H & 5.45 & 9.32 & 7.53 \\
\hline BD_1Hc/BD_0H & 5.20 & 9.09 & 7.45 \\
\hline
\end{tabular}

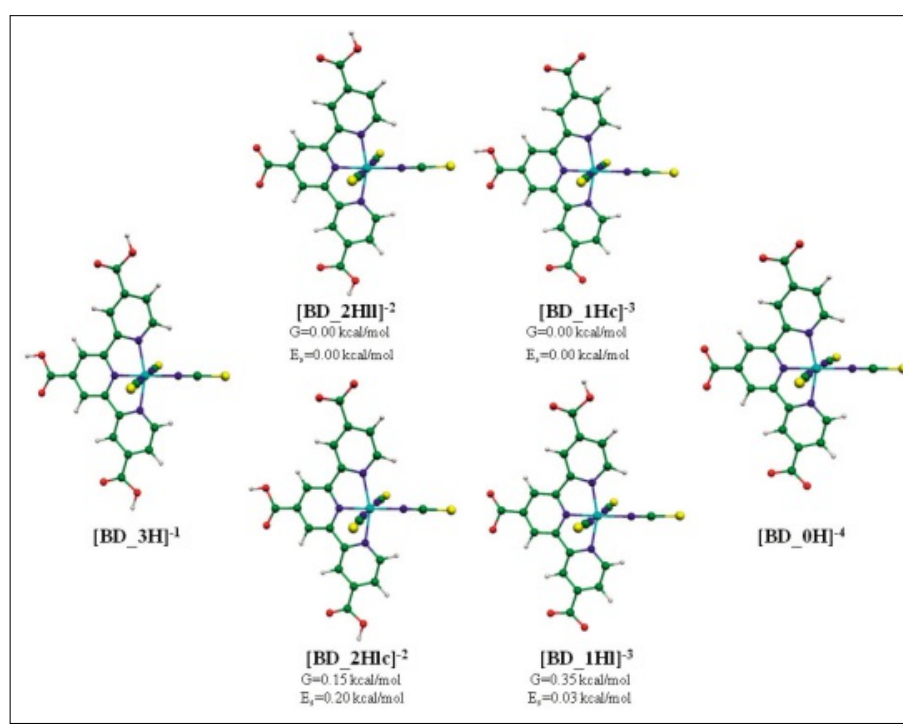

Fig. 2. Optimized molecular structures of BD_nH complexes. Relative free energies including thermal contribution $(\mathrm{G})$ and energy in solution from SCF calculations $\left(E_{s}\right)$ are reported for the possible tautomers.

ing the spheres on the acidic hydrogens since this approach has been provided an excellent agreement between theory and experiment for analogous Ru complexes. [56] The fully protonated species shows three possible deprotonation sites, the central carboxylic group (c) and the two lateral ones (1); the latter are equivalent at this stage, so we will consider only two deprotonation processes (Fig. 3). For the deprotonation of the central and of the lateral carboxyl groups we computed $\mathrm{pK}_{\mathrm{a} 1}$ values of 2.71 and 2.82, respectively. Due to the similarity of the two $\mathrm{pK}_{\mathrm{a} 1}$ values computed for the first deprotonation, we cannot discriminate between the occurrence of the deprotonation in the central or in the lateral site. Considering the second deprotonation step to start from the BD_2Hll species, we computed a $\mathrm{pK}_{\mathrm{a} 2}$ of 3.80 (4.06) for the deprotonation of the central (lateral) carboxyl group to give the BD_1Hl (BD_1Hc) species. On the other hand, hypothesizing that the first deprotonation takes place on the central carboxylic group (i.e. from the BD_2Hlc species), again two possible deprotonations are possible, one involving the central - $\mathrm{COOH}$ whose associated $\mathrm{pK}_{\mathrm{a} 2}$ is 3.69, another one in which the later carboxyl is deprotonated with a $\mathrm{pK}_{\mathrm{a}}$ constant of 3.95. Also for the second deprotonation step, the $\mathrm{pK}_{\mathrm{a}}$ is not very sensitive to the position from which the proton leaves $\left(3.69<\mathrm{pK}_{\mathrm{a} 2}<4.06\right)$, due to the small energy difference among the involved species. We compute two $\mathrm{pK}_{\mathrm{az}}$ values, 5.45 and 5.20, associated to the last deprotonation step of the lateral and central carboxylic groups, respectively.

Looking at our computed $\mathrm{pK}_{\mathrm{a}}$ constants, which are summarized in Fig. 3 , we notice i) each deprotonation step (mono-deprotonation, di-deprotonation and tri-deprotonation) shows very similar $\mathrm{pK}$ with deviations within $0.26 \mathrm{pK}$ unit, well below the methodology accuracy; ${ }^{[56}$ ii) different possible stepwise deprotonations are consistent with the experimental data; iii) the computed $\mathrm{pK}_{\mathrm{al}} \mathrm{s}$ and $\mathrm{pK}_{22} \mathrm{~s}$ are in good agreement with the experimental pK of 3.3, both the two computed series differing by less than one $\mathrm{pK}$ unit from the experimental value. Also the two computed $\mathrm{pK}_{\mathrm{a} 3} \mathrm{~s}$ are in excellent agreement with

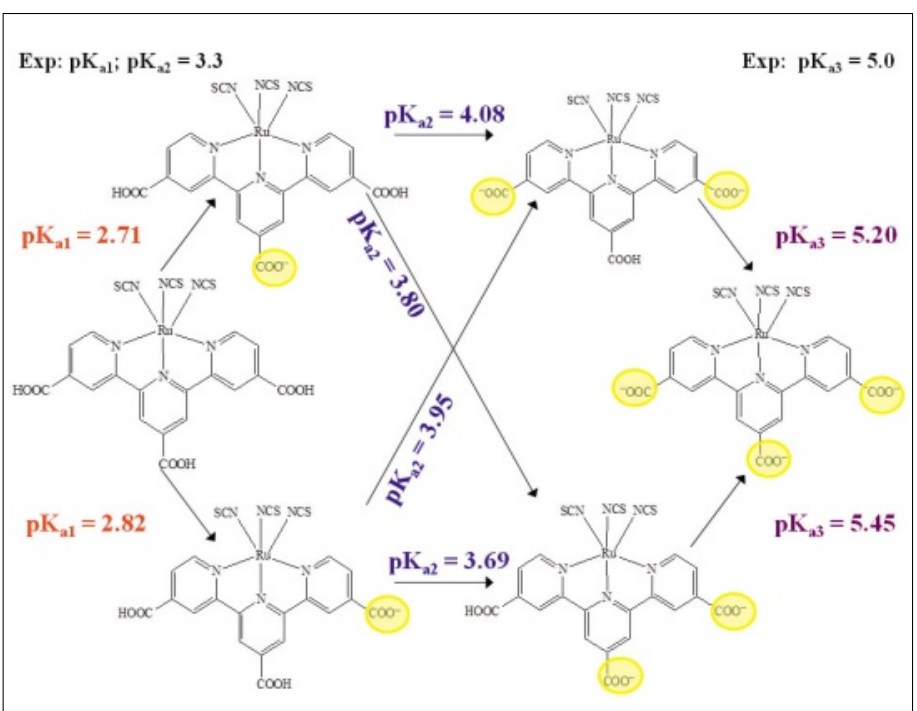

Fig. 3. Summary of the calculated deprotonation steps and $\mathrm{pK}_{\mathrm{a}} \mathrm{s}$ starting from the BD_3H species. 
Table 2. Comparison between calculated and experimental (second column of each entry) oxidation potentials for the various protonated/deprotonated forms of BD. ${ }^{a}$ Experimental oxidation potentials were measured $\mathrm{Ag} / \mathrm{AgCl}, \mathrm{SCE}$ and $\mathrm{Fc} / \mathrm{Fc}^{+}$are reported to the vacuum scale by adding 4.64, 4.68 and $4.84 \mathrm{eV}$, respectively.

\begin{tabular}{|c|c|c|c|c|c|c|}
\hline \multirow[b]{2}{*}{ BD_3H } & \multicolumn{2}{|c|}{ GSOP } & \multicolumn{2}{|l|}{$\mathrm{E}_{0-0}$} & \multicolumn{2}{|c|}{ ESOP } \\
\hline & 5.31 & $\begin{array}{l}5.36^{[1]} ; 5.34^{[7]} ; 5.24^{[9]} \\
5.16^{[54]} ; 5.15^{[54,55]}\end{array}$ & 1.59 & $1.61^{[7]}$ & 3.72 & $3.75^{[7]}$ \\
\hline BD_2Hlc & 5.07 & $5.35^{[1]} ; 5.23^{[55]}$ & 1.72 & & 3.35 & \\
\hline BD_1Hc & 5.05 & $\begin{array}{l}5.34^{[1]} ; 5.30^{[24,26]} \\
5.38^{[18]}\end{array}$ & 1.86 & $1.61^{[24]} ; 1.49^{[26]}$ & 3.10 & $\begin{array}{l}3.69^{[24]} ; \\
2.80^{[26]}\end{array}$ \\
\hline BD_0H & 5.01 & $5.18^{[1]}$ & 2.09 & & 2.92 & \\
\hline
\end{tabular}

the experimental values of 5.0. Taking into account these considerations, it is reasonable to suppose that different concurrent mono-deprotonation pathways and di-deprotonation pathways might occur in solution, and that it is difficult to discriminate among the various equilibria, moreover due to the small differences between the $\mathrm{pK}_{\mathrm{a} 1} \mathrm{~s}$ and $\mathrm{pK}_{\mathrm{a} 2} \mathrm{~s}$, it is quite difficult to define a unique pathway leading to the loss of two protons. We guess that the concomitant di-deprotonation experimentally measured is indeed the result of different equilibria characterized by similar dissociation constants involving species that are almost isoenergetic. As a consequence, none of the two proposed third-deprotonation processes can be ruled out on the basis of our computed data.

\subsection{Ground and Excited State Oxidation Potentials}

The GSOP and ESOP are two experimental crucial quantities both in absolute value and relative to the $\mathrm{I}_{3}^{-} / \mathrm{I}^{-}$oxidation potential and the $\mathrm{TiO}$ conduction band, respectively. Indeed, these parameters are directly related to the dye regeneration (GSOP) and excited state electron injection (ESOP). We set up a computational methodology to compute the GSOP and ESOP of dyes used in DSC, which has been demonstrated to be successful both for N3/ N719 dyes ${ }^{[49,57]}$ and a series of triphenylbased dyes.[58] The computed GSOP for the most stable BD_nHx species using the mixed basis set and adding specific spheres on the acidic hydrogen are reported in Table 2. A plethora of experimental measured values for the BD_nH series, are reported, with reference electrodes $\mathrm{Ag} / \mathrm{AgCl}, \mathrm{Fc} / \mathrm{Fc}^{+}$ and SCE, and different solvents. It is therefore difficult to find a correlation between the theoretical data and the experimental ones within all the BD_nHx complexes; in Table 2 we have collected all the experimental data found in literature, indicating the reference electrode used for the experiment. $[1,18,24,26,54,55]$ The experimental GSOP values show a decrease of $0.22 \mathrm{eV}$ going from the fully protonated species to the completely deprotonated one. A good agreement is found between theoretical and experimental data, computing a decrease in GSOP from BD_3H to BD_OH of $0.30 \mathrm{eV}$, even though within the series discrepancies are retrieved in the absolute value rather than in the qualitative trend.

The experimental ESOP value is determined as $\mathrm{E}^{*}\left(\mathrm{Ru}^{3+} p^{2+}\right)=\mathrm{E}\left(\mathrm{Ru}^{3+/ 2+}\right)-\mathrm{E}_{0-0}$, where the $\mathrm{E}_{0-0}$ value is estimated from the crossing point of the emission and absorption spectra. Different values have been found in literature referring to different degrees of protonation and different reference electrodes. ${ }^{[1,7,24,26,54,55]}$ Harakawa et al. estimated an $E^{*}\left(\mathrm{Ru}^{3+2+}\right)$ of 0.99 , taking as $\mathrm{E}_{0-0}$ the value $1.61 \mathrm{eV}^{[7]}$ and as $\mathrm{E}\left(\mathrm{Ru}^{3+/ 2+}\right)=0.66$ $\mathrm{V}$ and $0.62 \mathrm{~V}$ against SCE, ${ }^{[24]}$ for the fullyprotonated and mono-protonated species, respectively. $\mathrm{E}\left(\mathrm{Ru}^{3+/ 2+}\right)$ is determined using SCE as reference. According to a previously reported procedure, ${ }^{[49]}$ we computed the ESOP values for all the BD_xH species. The obtained results are reported in Table 2 within the experimentally available data for the fully protonated and monoprotonated species obtained by employing the same reference electrode used in the GSOP deteremination. It is interesting to note that the calculated $\Delta \mathrm{E}_{\mathrm{S} 0 \rightarrow \mathrm{S} 1}$ value for the fully protonated system nicely agrees with the measured $\mathrm{E}_{0-0}$. Our calculated data predict a substantial ESOP upshift upon depro- tonation of the carboxylic groups, which results from both a decrease of the GSOP and an increase of $\Delta \mathrm{E}_{\mathrm{S} 0 \rightarrow \mathrm{S} 1}$ values. Thus our results indicate a substantial increase in the driving force for electron injection into $\mathrm{TiO}_{2}$ upon deprotonation of the BD. We also note, however, that the electronic properties of the $\mathrm{TiO}_{2}$-adsorbed dye are usually similar to that of the fully protonated systems. ${ }^{[49,59]}$

\subsection{Electronic Structure and Absorption Spectra}

In Fig. 4 we report the energy levels of the frontier molecular orbitals for all the investigated species together with isodensity surface plots of BD_3H selected orbitals. Going from BD_3H to BD_0H we observe both the highest occupied molecular orbitals (HOMOs) and lowest occupied molecular orbitals (LUMOs) are destabilized; however, while we computed a stabilization of the HOMO by $c a .0 .07$ to $0.15 \mathrm{eV}$ for species which differ by the presence of only one proton, a larger stabilization of the LUMO is computed, leading to a difference of $0.48 \mathrm{eV}$ between the LUMO of BD_0H and BD_1H. The HOMO-LUMO gap $\left(\Delta \mathrm{E}_{\mathrm{H}-\mathrm{L}}\right)$ energy increases as a function of the deprotonation as we already observed for deprotonated forms of $\mathrm{N} 3$ dye. [14]

For BD_3H, the first two HOMOs are almost degenerate and are an antibonding combination of the $R u d_{x z} / d_{y z}$ with $\operatorname{SCN} \pi$ orbitals of all the three ligands. At lower energies we computed the mixed $\mathrm{Ru} \mathrm{d}_{\mathrm{xy}}$ SCN $\pi$, involving only the ligand on the $x$ axis. The HOMO-3-HOMO-5 are the lone pairs orbitals of the SCN ligands, while HOMO-6/HOMO-8 are the counterpart bonding combinations between the Ru- $\mathrm{t}_{2}$ and the s-p orbitals. The LUMO/LUMO+3 are $\pi$ orbitals on the terpyridine ligands including the carboxylic groups and with variable percentage of Ru orbital. The deprotonation of one of the lateral carboxylic

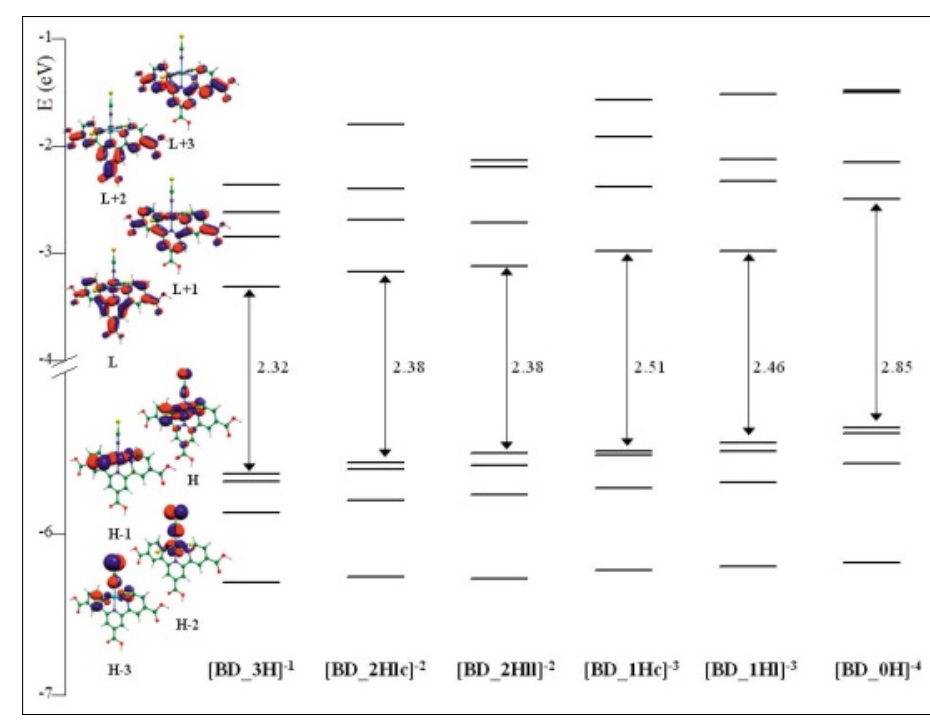

Fig. 4. Energies of selected frontier molecular orbitals and of the HOMO-LUMO gap for all the investigated BD species. Isodensity surface plots (contour value $=0.035$ a.u.) of the BD_3H frontier molecular orbitals are reported. 
groups does not imply a relevant change in the nature and relative energies of the first HOMOs, even though a few orbitals on the COO-group insert between the SNC orbitals and the bonding combination $\mathrm{Ru} / \mathrm{SCN}$. The first LUMOs present an asymmetrical charge distribution on the terpyridine with respect to the BD_3H complex. LUMO/LUMO+1 are delocalized essentially on the rings of tpy bearing the carboxylic group, while those at higher energies mainly present contributions from the carboxylated pyridine. Also the deprotonation of the other peripheral carboxylic group, leading to the BD_1H complex, does not have a sizable response on the first HOMOs, apart from the destabilization of $\mathrm{COO}^{-}$based $\pi$ orbitals which become the HOMO-6/HOMO-7. On the other hand changes in the charge distribution are retrieved in the first LUMOs, which show asymmetrical electronic distribution with respect to $\mathrm{BD} \_3 \mathrm{H}$, with the LUMO still delocalized on the portion of tpy bearing the only $\mathrm{COO}^{-}$. The fully deprotonated species show a similar electronic charge distribution associated to the first HOMOs and LUMOs comparing to the other investigated species. Also for this species, as for the other deprotonated ones, destabilized occupied orbitals insert between the SCN orbitals series and the bonding Ru-SCN orbitals. The LUMO, delocalized on the tpy does not show significant contributions from the $\mathrm{COO}^{-}$groups, which on the other hand are present in the LUMO+1/ LUMO+3 set.

We now discuss the optical properties of $\mathrm{BD}$, as a function of the solution $\mathrm{pH}$. We have used in the present study four complexes characterized by different degrees of protonation, which represent the species present in solution at different $\mathrm{pH}$ values. Bearing in mind the results obtained from $\mathrm{pK}_{\mathrm{a}}$ constant calculations, it is very difficult to describe the $\mathrm{pH}$-dependent spectral evolution as the result of a series of spectra associated to single species or to two species in equilibrium between themselves. The theoretical results point out that more than one equilibrium should be compatible with a certain $\mathrm{pH}$ range, moreover the similar stability of the considered species supports the idea that the different conformers are present in solution with similar weight. We have simulated the UV-VIS absorption spectra of the four most stable BD_xH species, which however represent limit situations and allow us to investigate in depth how the deprotonation affects the optical properties, even though providing a partial description of the BD complexity.

In Fig. 5 the simulated spectra of BD_xH (with $\mathrm{x}=0-3$ ) are reported in the wavelengths range of $270-900 \mathrm{~nm}$, the main transitions responsible for the spectral features in the visible (up to $400 \mathrm{~nm}$ ) are reported in Table 3 . The fully protonated species shows an absorption band at $c a .700 \mathrm{~nm}$ with a tail in the NIR region. A more intense band has been computed at $491 \mathrm{~nm}$ followed by a UV band. The lowest absorption band originates essentially from two transitions, $\mathrm{S}_{0}-\mathrm{S}_{1}$ and $\mathrm{S}_{0}-\mathrm{S}_{3}$ (Table 3) which have HOMO-1 $\rightarrow$ LUMO and $\mathrm{HOMO} \rightarrow$ LUMO character. Bearing in mind the electronic structure of the BD_3H species this absorption band can be assigned as a metal to ligand charge transfer (MLCT) transition from mixed $\mathrm{Ru} \mathrm{d} / \mathrm{d}_{\mathrm{yz}}$ and SCN $\pi$ states to a state delocalized on the terpyridine including the carboxylic groups and with small metal participation. Also the band at 491 $\mathrm{nm}$, given rise by the states $\mathrm{S}_{0}-\mathrm{S}_{4} \mathrm{~S}_{0}-\mathrm{S}_{8}$, $\mathrm{S}_{0}-\mathrm{S}_{9}$ and $\mathrm{S}_{0}-\mathrm{S}_{11}$, has been assigned as an MLCT with a small contribution $\left(S_{0}-S_{11}\right)$ of LL'CT from the SCN ligand to the tctpy moiety. The deprotonation of the central $\mathrm{COOH}$ group is reflected by a blue-shift of the two visible absorption bands with respect to the BD_3H spectrum. The lowest absorption band extends between 520 and $900 \mathrm{~nm}$ and is characterized by two maxima at $698 \mathrm{~nm}$ and $580 \mathrm{~nm}$. From an inspection of the TDDFT eigenvectors, we assigned this absorption band as a MLCT one, the transitions originating this band involve the HOMO and HOMO-1 as starting states and LUMO-LUMO+1 as final states (see Table 3). The main difference between BD_3H and BD_2Hll is the different charge distribution of starting states of the transitions, which in BD_2Hll are essentially delocalized in the protonated part of the tpy ligand. The absorption band at $440 \mathrm{~nm}$ is a MLCT transition with contribution coming from SCN to tctpy $\pi-\pi^{*}$ transitions.

The lowest BD_1Hc absorption maximum, compared to the experimental absorption spectrum in Fig. 6, is computed at $605 \mathrm{~nm}$, blue-shifted with respect to the corresponding BD_3H and BD_2Hll absorption bands. This absorption band originates from an intense $\mathrm{S}_{0}-\mathrm{S}_{3}$ excitation of mainly $\mathrm{HOMO} \rightarrow$ LUMO character. Analogously to the BD_2Hll complex, the final state of this transition is delocalized on the terpyridine involving the carboxylic groups. The transitions $\mathrm{S}_{0}-\mathrm{S}_{4}$ and $\mathrm{S}_{0}-\mathrm{S}_{6}$ computed at higher energies, have as final state the LUMO+1 which also is delocalized on the tpy ligand with a contribution from the carboxylic group. These two transitions are responsible for a spectral MLCT feature at $c a .495 \mathrm{~nm}$. At $415 \mathrm{~nm}$, we retrieved a mixed MLCT/ $\pi-\pi *(\mathrm{SCN}$ to tpy) absorption band, while we assigned the absorption band computed at $359 \mathrm{~nm}$ as a $\pi-\pi^{*}$ within the terpyridine framework. Overall, the agreement between theory and experiment is very good, with our calculations nicely reproducing all the main experimental spectral features, including their relative intensity. The simulated absorption spectrum of BD_OH shows a large and almost flat absorption band between 470-600 nm, with a long tail extending up to $700 \mathrm{~nm}$. Four MLCT transitions of comparable intensity, $\mathrm{S}_{0}-\mathrm{S}_{1} \mathrm{~S}_{0}-\mathrm{S}_{3} \mathrm{~S}_{0}-\mathrm{S}_{4}$ and $\mathrm{S}_{0}-\mathrm{S}_{5}$ are responsible for this band, which is blue-shifted with respect to the corresponding one of the fully and partially protonated species. At higher energies an intense $\pi-\pi *$ within the terpyridine framework was computed at $331 \mathrm{~nm}$, this band shows a shoulder of MLCT character at $382 \mathrm{~nm}$

\section{Adsorption Geometry and Electronic Structure of $\mathrm{TiO}_{2}-$ adsorbed Black Dye}

The adsorption of Black Dye onto $\mathrm{TiO}_{2}$ surfaces has been the subject of a few recent theoretical and computational investigations, using both cluster and periodic boundary conditions approaches. ${ }^{[34-36]}$ Here we explored three possible adsorp-

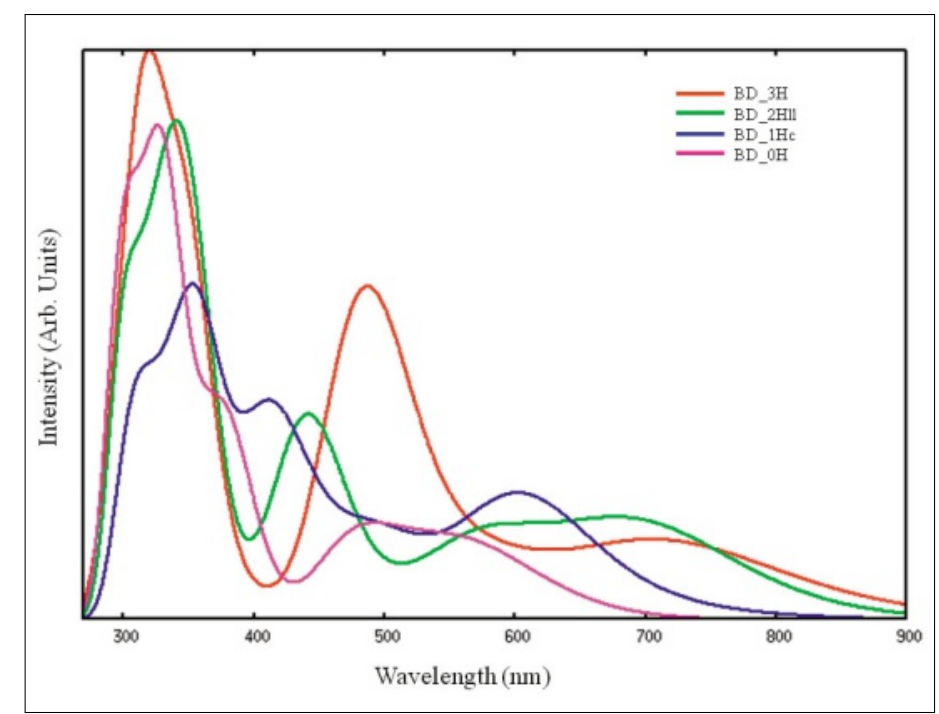

Fig. 5. Comparison between computed spectra of BD_3H (red lines), BD_2HII (green lines), BD_1Hc (blue lines) and BD_OH (magenta lines) in water solution. 
Table 3. Computed excitation energies (eV and $\mathrm{nm}$ ) and oscillator strengths ( $\mathrm{f}$ ) for the optical transitions of BD_3H, BD_2HII, BD_1Hc, BD_OH.

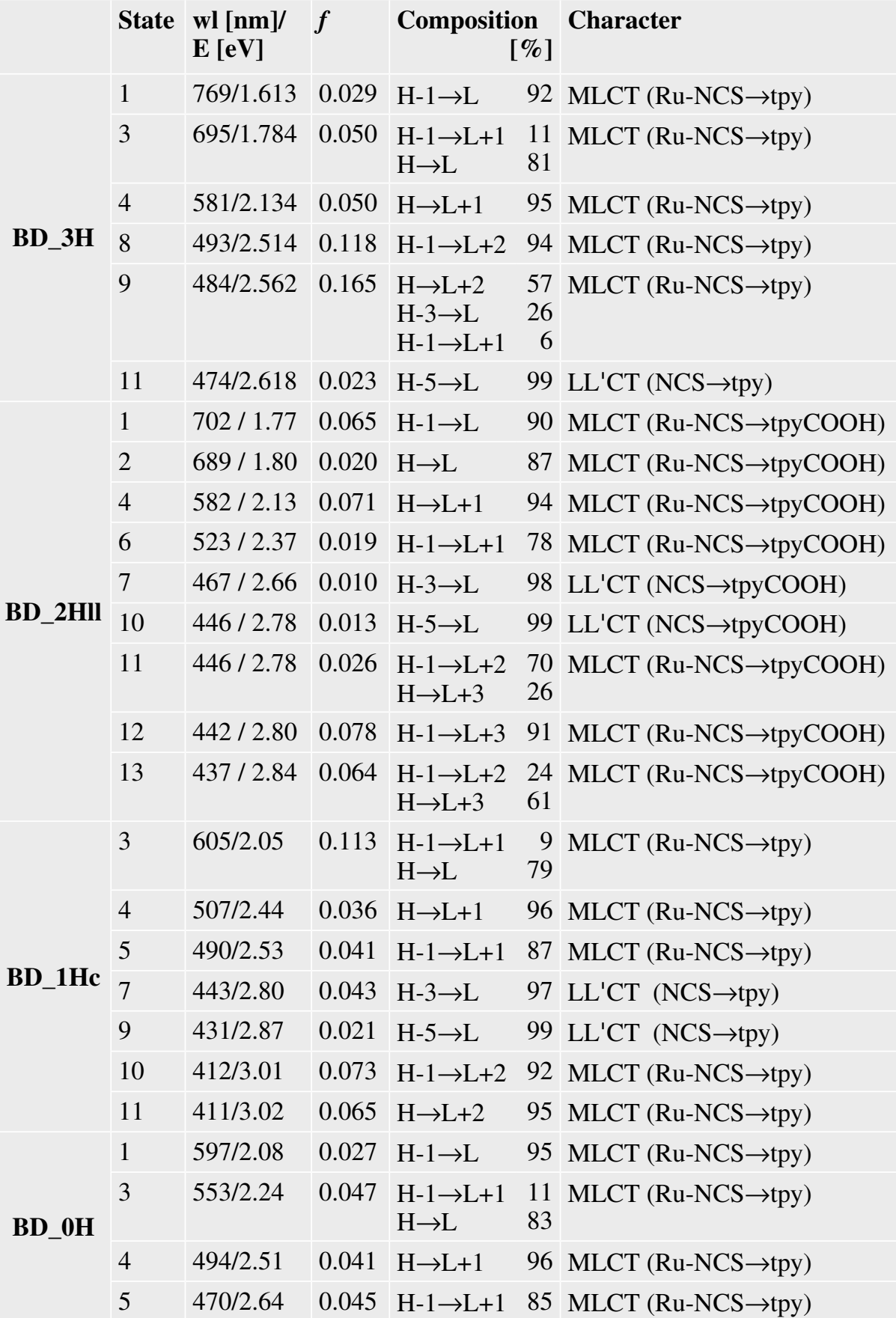

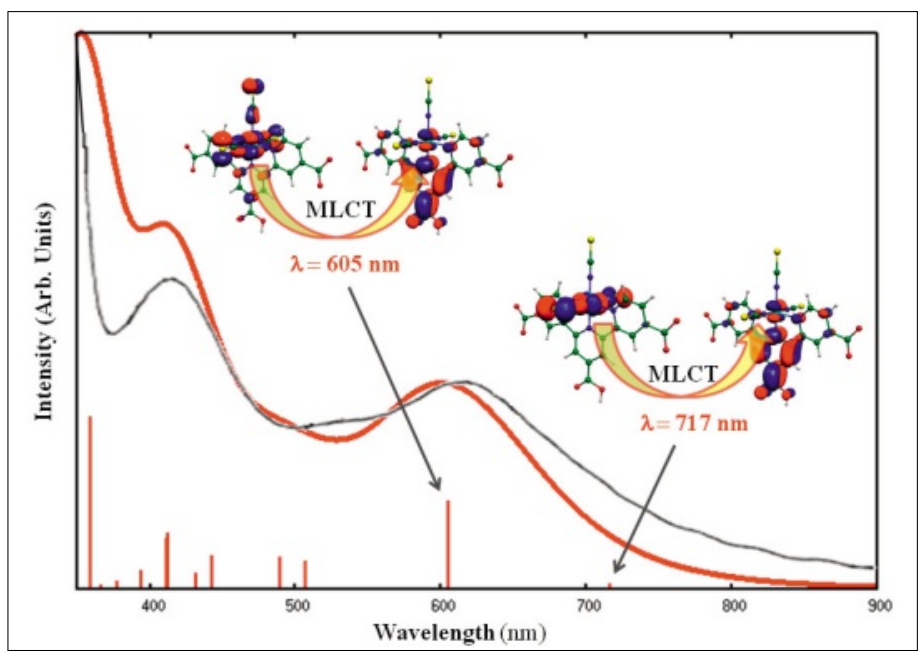

Fig. 6. Comparison between computed spectra of BD_1Hc (red lines) in water solution and experimental absorption data recorded in ethanolic solution adapted from ref. [18] (black lines). Red vertical lines correspond to calculated excitation energies and oscillator strengths for BD_H1c. tion modes for the BD_2H species on $\mathrm{TiO}_{2}$. The choice of looking at the doubly protonated species was made here to allow a straightforward comparison of the BD and N719 dye carrying two protons, ${ }^{[59,60]}$ which have the same -2 total charge. In Fig. 7 we report the calculated adsorption mode for N719 and for the three considered BD adsorption modes, labeled as a-c. For all the three structures we considered the two dye protons as being located in the proximity of the $\mathrm{TiO}_{2}$ surface. In all cases the BD adsorbs on $\mathrm{TiO}_{2}$ using two of the three available carboxylic groups. The starting structure (Fig. 7a) originated from that calculated for N719 and is characterized by dissociated bridged bidentate and monodentate anchoring of the two carboxylic groups. In this structure, one of the three NCS groups points towards the $\mathrm{TiO}_{2}$ surface. Structure b, on the other hand, is similar to the typical adsorption mode found for heteroleptic ruthenium dyes, ${ }^{[61,62]}$ and features two dissociated monodentate carboxylic groups. Structure $\mathrm{c}$ is somehow intermediate between a and c, showing a similar orientation with respect to the $\mathrm{TiO}_{2}$ surface to $b$ but an anchoring pattern close to that of a. Our calculations indicate structure $b$ to be the more stable structure, followed by $\mathrm{c}$ and $\mathrm{a}$. This data differs from what was reported by Sodeyama et al. ${ }^{[34]}$ for the fully protonated $\mathrm{BD}$ on a periodic $\mathrm{TiO}_{2}$ slab in vacuo, who found a single bidentate carboxylic anchoring as the most stable structure. The different number of protons, the cluster vs. periodic approach and the inclusion of solvation effects in our calculations are the most likely reasons for the different adsorption modes.

A comparison of the electronic structure and alignment of energy levels for N719 and the most stable BD structure b is reported in Fig. 8. Notice that in this Fig. we use data for N719 obtained for the fully interacting system, ${ }^{[59]}$ while for the BD we employ the HOMO energy calculated for structure $b$ at the same B3LYP/3-21G* level used for N719 but for the lowest excitation energy (of singlet and triplet nature) we resort to the more computationally convenient data for the BD_2H species in solution at the same level of theory. It is interesting to note that for the $\mathrm{TiO}_{2}$-adsorbed dyes, the BD maintains a slightly lower (i.e. less positive) oxidation potential compared to N719. It is also interesting to observe that the alignment of excited state energy levels for the BD leads to a reduced driving force for electron injection compared to N719. For N719 we calculate a lowest driving force of $0.33 \mathrm{eV}$, which reduces to $0.09 \mathrm{eV}$ for the BD. Although the BD data is not totally quantitative, being based on data on the isolated dye in solution rather than for the adsorbed dye, our results clearly suggest a problematic electron injection 


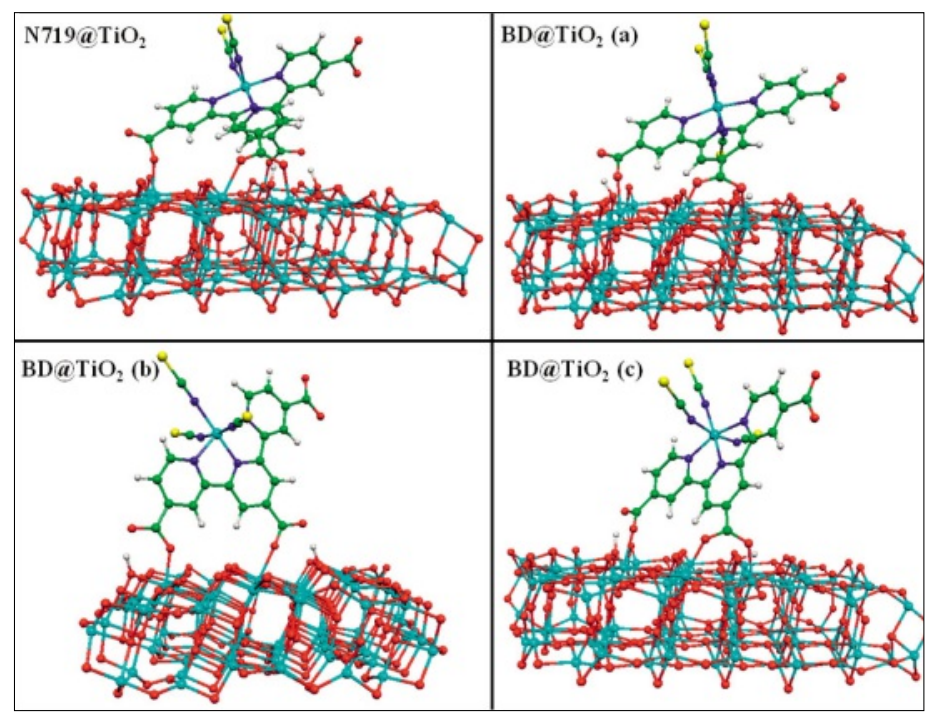

Fig. 7. Adsorption geometry of N719 on $\mathrm{TiO}_{2}$ (top, left) and of $\mathrm{BD}$ on $\mathrm{TiO}_{2}$ in the configurations $\mathrm{a}, \mathrm{b}$ and $c$ as described in the text.

for the $\mathrm{BD}$, due to the lower coupling with the $\mathrm{TiO}_{2}$ DOS compared to N719. The situation is even more severe if one considers the lowest triplet excited state for the BD, which being calculated $0.15 \mathrm{eV}$ below the lowest singlet state, could lead to an energetically unfavorable electron injection from this state. It is thus clear how tuning of the $\mathrm{TiO}_{2}$ conduction band energy by potential determining ions is crucial to achieve high efficiency in DSCs based on Black Dye.

\section{Conclusions}

We have reported an exhaustive theoretical and computational investigation of the electronic, optical, redox and acid/ base properties, along with the adsorption mode on $\mathrm{TiO}_{2}$, of Black Dye, the prototypical panchromatic dye for solar cells applications. The BD is nowadays employed in DSCs which provide the highest certified efficiency of $11.4 \% .^{[15]}$ One interesting feature of the $\mathrm{BD}$ is the demonstrated sensitivity of the properties of this system to the solution $\mathrm{pH}$. This is related to the three carboxylic acidic groups on the tpy ligand, which directly influence the energy and composition of the $\pi^{*}$ orbitals of the ligand. We thus investigated in detail the variation of the relevant dye properties as a function of the solution $\mathrm{pH}$, corresponding to the stepwise deprotonation of the carboxylic groups. Our results reproduced the expected blue-shift of the optical absorption spectrum and the experimental trend of oxidation potentials by increasing $\mathrm{pH}$, which turned both out to be in excellent agreement with experimental values. Also our calculated excited state oxidation potential is in good agreement with available experimental data. We then looked at the $\mathrm{pK}_{\mathrm{a}}$ of the various deprotonation steps, finding lowest $\mathrm{pK}$ values for the stepwise dissociation of three protons of $2.71,3.69$ and 5.20, in excellent agreement with experimental $\mathrm{pK}$ values of 3 and 5, for two and one proton dissociation, respectively. Due to the similarity of various deprotonation steps, however, a clearcut assignment of the species effectively present in solution was not possible.

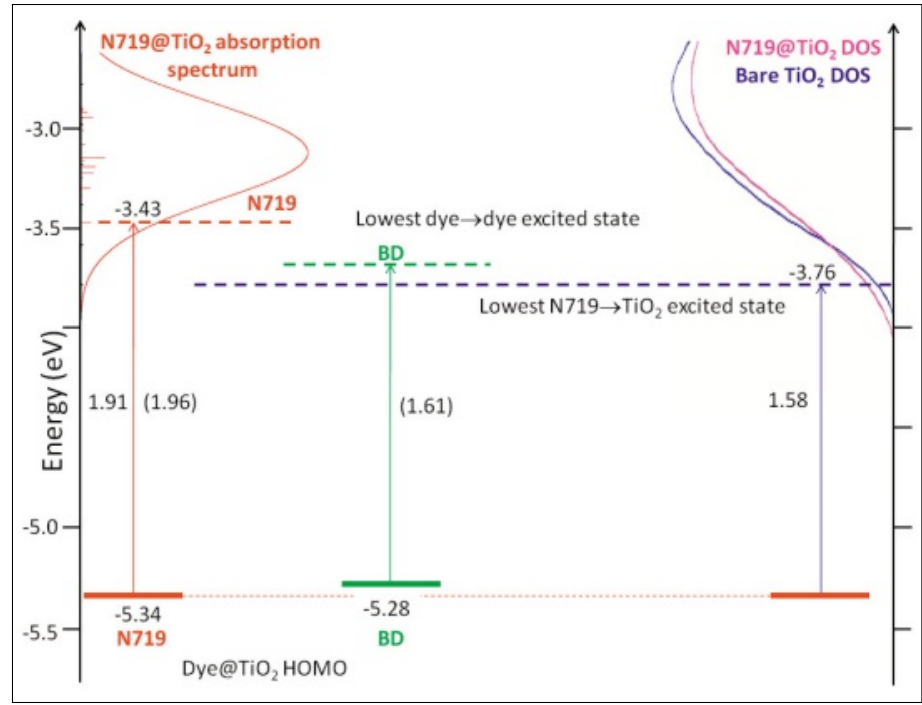

Fig. 8. Alignment of ground and excited state energy levels for N719 and BD_2H adsorbed on $\mathrm{TiO}_{2}$ calculated at the B3LYP/3-21G* level of theory. Data in parenthesis refer to data in solution for the isolated dyes. The excitation energies refer to singlet-singlet states.
Finally we investigated the adsorption of $\mathrm{BD}$ on $\mathrm{TiO}_{2}$, and considered three adsorption modes, comparing the results to those previously obtained for the related N719 dye. For the doubly protonated BD species, we found the most stable adsorption to occur via two dissociated monodentate carboxylic groups. Inspection of the electronic structure and alignment of energy levels for N719 and BD revealed a reduced driving force for electron injection in the latter dye, which could possibly lead to energetically unfavorable electron transfer from the oxidized dye to the $\mathrm{TiO}_{2}$ conduction band.

Our results, obtained in a coherent fashion, constitute a reference study for future investigations and optimization of BD-based dye-sensitized solar cells.

\section{Acknowledgment}

We thank FP7-ENERGY-2010 project "ESCORT" 261920 and MIUR-PRIN 2008 for financial support.

Received: December 21, 2012

[1] M. K. Nazeeruddin, P. Pèchy, T. Renouard, S M. Zakeeruddin, R. Humphry-Baker, P. Comte, P. Liska, L. Cevey, E. Costa, V. Shklover, L. Spiccia, G. B. Deacon, C. A. Bignozzi, M. Grätzel, J. Am. Chem. Soc. 2001, 123, 1613.

[2] A. Abbotto, F. Sauvage, C. Barolo, F. De Angelis, S. Fantacci, M. Grätzel, N. Manfredi, C. Marinzi, M. K. Nazeeruddin, Dalton Trans. 2011, 40, 234.

[3] T. Kinoshita, J.-i. Fujisawa, J. Nakazaki, S Uchida, T. Kubo, H. Segawa, J. Phys. Chem. Lett. 2012, 3, 394.

[4] T. Yamaguchi, T. Miyabe, T. Ono, H. Arakawa Chem. Commun. 2010, 46, 5802.

[5] S. Altobello, R. Argazzi, S. Caramori, C. Contado, S. Da Frè, P. Rubino, C. Chonè, G. Larramona, C. A. Bignozzi, J. Am. Chem. Soc. 2005, 127, 15342 .

[6] B.-S. Chen, K. Chen, Y.-H. Hong, W.-H. Liu, T.-H. Li, C.-H. Lai, P.-T. Chou, Y. Chi, G.-H. Lee, Chem. Commun. 2009, 5844.

[7] A. Islam, H. Sugihara, H. Arakawa, J. Photochem. Photobiol. A 2003, 158, 131.

[8] J.-H. Yum, E. Baranoff, S. Wenger, M. K. Nazeeruddin, M. Grätzel, Energy Environ. Sci. 2011, 4, 842 .

[9] M. K. Nazeeruddin, P. Pechy, M. Grätzel, Chem. Commun 1997, 1705.

[10] B. O'Regan, M. Grätzel, Nature 1991, 353, 737.

[11] M. Grätzel, Nature 2001, 414, 338.

[12] M. Grätzel, Inorg. Chem. 2005, 44, 6841

[13] A. Hagfeldt, G. Boschloo, L. Sun, L. Kloo, H Pettersson, Chem. Rev. 2010, 110, 6595.

[14] M. K. Nazeeruddin, F. De Angelis, S. Fantacci, A. Selloni, G. Viscardi, P. Liska, S. Ito, B Takeru, M. Grätzel, J. Am. Chem. Soc. 2005 , 127,16835 .

[15] L. Han, A. Islam, H. Chen, C. Malapaka, B. Chiranjeevi, S. Zhang, X. Yang, M. Yanagida, Energy Environ. Sci. 2012, 5, 6057.

[16] A. Yella, H.-W. Lee, H. N. Tsao, C. Yi, A. K. Chandiran, M. K. Nazeeruddin, E. W.-G. Diau, C.-Y. Yeh, S. M. Zakeeruddin, M. Grätzel, Science 2011, 334, 629.

[17] C. Bauer, G. Boschloo, E. Mukhtar, A. Hagfeldt, J. Phys. Chem. B 2002, 106, 12693.

[18] A. Reynal, A. Forneli, E. Palomares, Energy Environ. Sci. 2010, 3, 805. 
[19] R. Katoh, A. Furube, M. Kasuya, N. Fuke, N. Koide, L. Han, J. Mater. Chem. 2007, 17, 3190.

[20] R. Katoh, M. Kasuya, A. Furube, N. Fuke, N. Koide, L. Han, Sol Energy Mater. Sol. Cells 2009, 93, 698 .

[21] R. Katoh, M. Kasuya, S. Kodate, A. Furube, N. Fuke, N. Koide, J. Phys. Chem. C 2009, 113, 20738.

[22] K. Hara, T. Nishikawa, M. Kurashige, H Kawauchi, T. Kashima, K. Sayama, K. Aika, H. Arakawa, Sol. Energy Mater. Sol. Cells 2005, 85, 21.

[23] M. Yanagida, K. Miyamoto, K. Sayama, K. Kasuga, M. Kurashige, S. Takano, G. Fujihashi, Y. Abe, H. Sugihara, Electrochim. Acta 2006, $51,3993$.

[24] Z.-S. Wang, T. Yamaguchi, H. Sugihara, H. Arakawa, Langmuir 2005, 21, 4272.

[25] Z.-S. Wang, G. Zhou, J. Phys. Chem. C 2009 , $113,15417$.

[26] G. C. Vougioukalakis, T. Stergiopoulos, G. Kantonis, A. G. Kontos, K. Papadopoulos, A. Stublla, P. G. Potvin, P. Falaras, J. Photochem. Photob. A 2010, 214, 22.

[27] F. Aiga, T. Tada, J. Mol. Struc. 2003, 658, 25.

[28] S. Ghosh, G. K. Chaitanya, K. Bhanuprakash, M. K. Nazeeruddin, M. Grätzel, R. P. Yella, Inorg. Chem. 2006, 45, 7600.

[29] M.-X. Li, H.-X. Zhang, X. Zhou, Q.-J. Pan, H.G. Fu, C.-C. Sun, Eur. J. Inorg. Chem. 2007, 2171.

[30] A. Govindasamy, Chen, H. Tsuboi, M. Koyama, A. Endou, H. Takaba, M. Kubo, C. A. Del Carpio, A. Miyamoto, Jpn. J. Appl. Phys. 2007, 46, 2655.

[31] M.-X. Li, X. Zhou, B.-H. Xia, H.-X. Zhang, Q.-J. Pan, T. Liu, H.-G. Fu, C.-C. Sun, Inorg. Chem. 2008, 47, 2312.

[32] H. Kusama, H. Sugihara, K. Sayama, J. Phys. Chem. C 2011, 115, 9267.

[33] S. Y. Bang, M. J. Ko, K. Kim, J. H. Kim, I.-H. Jang, N.-G. Park, Synth. Met. 2012, 162, 1503.

[34] K. Sodeyama, M. Sumita, C. O'Rourke, U. Terranova, A. Islam, L. Han, D. R. Bowler, Y. Tateyama, J. Phys. Chem. Lett. 2012, 3, 472.

[35] S.-H. Liu, H. Fu, Y.-M. Cheng, K.-L. Wu, S.-T.
Ho, Y. Chi, P.-T. Chou, J. Phys. Chem. C 2012, 116, 16338.

[36] J. Chen, F.-Q. Bai, J. Wang, L. Hao, Z.-F. Xie, Q.-J. Pan, H.-X. Zhang, Dyes Pigm. 2012, 94, 459.

[37] G. W. T. M. J. Frisch, H. B. Schlegel, G. E. Scuseria, M. A. Robb, J. R. Cheeseman, J. A. Montgomery, Jr., T. Vreven, K. N. Kudin, J. C. Burant, J. M. Millam, S. S. Iyengar, J. Tomasi, V. Barone, B. Mennucci, M. Cossi, G. Scalmani, N. Rega, G. A. Petersson, H. Nakatsuji, M. Hada, M. Ehara, K. Toyota, R. Fukuda, J. Hasegawa, M. Ishida, T. Nakajima, Y. Honda, O. Kitao, H. Nakai, M. Klene, X. Li, J. E. Knox, H. P. Hratchian, J. B. Cross, V. Bakken, C. Adamo, J. Jaramillo, R. Gomperts, R. E. Stratmann, O. Yazyev, A. J. Austin, R. Cammi, C. Pomelli, J. W. Ochterski, P. Y. Ayala K. Morokuma, G. A. Voth, P. Salvador, J. J. Dannenberg, V. G. Zakrzewski, S. Dapprich, A. D. Daniels, M. C. Strain, O. Farkas, D. K. Malick, A. D. Rabuck, K. Raghavachari, J. B. Foresman, J. V. Ortiz, Q. Cui, A. G. Baboul, S. Clifford, J. Cioslowski, B. B. Stefanov, G. Liu, A. Liashenko, P. Piskorz, I. Komaromi, R. L. Martin, D. J. Fox, T. Keith, M. A. Al-Laham, C Y. Peng, A. Nanayakkara, M. Challacombe, P. M. W. Gill, B. Johnson, W. Chen, M. W. Wong, C. Gonzalez, J. A. Pople, Gaussian 03, Revision C.02. Gaussian, Inc., Wallingford, CT, 2004.

[38] A. D. Becke, J. Chem. Phys. 1993, 98, 5648.

[39] P. J. Hay, R. W. Willard, J. Chem. Phys. 1985, 82, 299.

[40] V. A. Rassolov, M. A. Ratner, J. A. Pople, P. C. Redfern, L. A. Curtiss, J. Comput. Chem. 2001, 22, 976.

[41] A. R. Vitaly, A. P. John, A. R. Mark, L. W. Theresa, J. Chem. Phys. 1998, 109, 1223.

[42] E. S. S. Miertš, J. Tomasi, Chem. Phys. 1981, 55,117

[43] M. Cossi, V. Barone, R. Cammi, J. Tomasi, Chem. Phys. Lett. 1996, 255, 327.

[44] N. Godbout, D. R. Salahub, J. Andzelm, W. Erich, Can. J. Chem. 1992, 70, 560.

[45] V. Barone, M. Cossi, J. Tomasi, J. Chem. Phys. 1997, 107, 3210.
[46] G. A. A. Saracino, R. Improta, V. Barone, Chem. Phys. Lett. 2003, 373, 411.

[47] I. A. Topol, G. J. Tawa, S. K. Burt, A. A. Rashin, J. Chem. Phys. 1999, 111, 10998

[48] M. D. Tissandier, K. A. Cowen, W. Y. Feng, E. Gundlach, M. H. Cohen, A. D. Earhart, J. V. Coe, T. R. Tuttle, J. Phys. Chem. A 1998, 102, 7787.

[49] F. De Angelis, S. Fantacci, A. Selloni, Nanotechnology 2008, 19, 424002.

[50] A. Vittadini, A. Selloni, F. P. Rotzinger, M. Grätzel, Phys. Rev. Lett. 1998, 81, 2954.

[51] M. J. Lundqvist, M. Nilsing, P. Persson, S. Lunell, Int. J. Quantum Chem. 2006, 106, 3214.

[52] F. De Angelis, S. Fantacci, E. Mosconi, M. K. Nazeeruddin, M. Grätzel, J. Phys. Chem. C 2010, 115, 8825.

[53] F. De Angelis, S. Fantacci, A. Selloni, M. K. Nazeeruddin, M. Grätzel, J. Phys. Chem. C 2011, 114, 6054 .

[54] G. Wolfbauer, A. M. Bond, G. B. Deacon, J. Howitt, D. MacFarlane, L. Spiccia, J. Electrochem. Soc. 2001, 148, 97.

[55] G. Wolfbauer, A. M. Bond, G. B. Deacon, D. R. MacFarlane, L. Spiccia, J. Electroanal. Chem. 2000, 490, 7.

[56] G. Pizzoli, M. G. Lobello, B. Carlotti, F. Elisei, M. K. Nazeeruddin, G. Vitillaro, F. De Angelis, Dalton Trans. 2012, 41, 11841.

[57] A. Vlcek Jr, S. Zalis, Coord. Chem. Rev. 2007, 251, 258.

[58] M. Pastore, S. Fantacci, F. De Angelis, J. Phys. Chem. C 2010, 114, 22742.

[59] F. De Angelis, S. Fantacci, E. Mosconi, M K. Nazeeruddin, M. Grätzel, J Phys. Chem. C 2011, 115,8825 .

[60] F. De Angelis, S. Fantacci, A. Selloni, M. K. Nazeeruddin, M. Grätzel, J. Phys. Chem. C 2010, 114, 6054

[61] F. De Angelis, G. Vitillaro, L. Kavan, M. K. Nazeeruddin, M. Grätzel, J. Phys. Chem. C 2012, 116, 18124.

[62] M. Pastore, F. D. Angelis, J. Phys. Chem. Lett. 2012, 3, 2146. 